\title{
Revisiting head circumference of Brazilian newborns in public and private maternity hospitals
}

\author{
Revisitando o perímetro craniano de recém nascidos brasileiros de maternidades \\ públicas e privadas
}

Maria do Socorro Teixeira Amorim ${ }^{1}$, Aurea Nogueira de Melo ${ }^{1}$

\begin{abstract}
Objective: To revisit the head circumference $(\mathrm{HC})$ of newborns in public and private maternity hospitals; to correlate our findings with the gestational age, gender, and type of delivery; and build and validate graphs and curves. Methods: This was a prospective study performed on healthy newborns. Differences in $\mathrm{HC}$ were analyzed as a function of gestational age, gender, the healthcare system and the type of delivery. Smoothed percentile curves were created using the least mean squares method. Results: Of the included newborns, 697 were born in private maternity hospitals and 2,150 were born in public maternity hospitals. In all, 839 were born by vaginal delivery, and 1,311 were born by cesarean delivery. At 37 to 42 weeks of gestation, male newborns had a larger HC than females. Infants born in private maternity and those born by cesarean delivery had a larger HC. Conclusion: An important result of the present study is that our analyses allowed us to generate curves and statistically-validated graphs that can be used in clinical neonatal practice.
\end{abstract}

Keywords: neonatal head circumference; gestational age; gender; public and private maternity; newborn.

RESUMO

Objetivo: Revisitar o perímetro cefálico (PC) de recém nascidos (RN) correlacionando com a idade gestacional (IG), gênero, tipo de parto (TP), sistema de saúde e construir e validar gráficos e curvas. Métodos: Estudou-se prospectivamente RN sadios analisando-se as diferenças entre os PC segundo a IG, gênero, TP e sistema de saúde. As curvas suavizadas de percentis foram criadas pelo método LMS (least mean squares). Resultados: 692 nasceram em maternidades privadas, 2.150 em maternidade pública, 839 nasceram de parto vaginal e 1.311 parto cesáreo. 0 gênero masculino apresentou PC maior que o feminino nas IG de 37 a 42 semanas. Os RN de maternidades privadas tiveram PC maior que os de maternidade pública. Os nascidos de parto cesáreo tiveram PC maior que os de parto vaginal. Conclusão: Importante consequência deste estudo foi que os resultados permitiram a criação de curvas e gráficos validados estatisticamente de aplicabilidade na prática clínica neonatal.

Palavras-chave: perímetro craniano neonatal; idade gestacional; gênero; maternidades pública e privadas; recém nascido.

In newborns, measurements of head circumference $(\mathrm{HC})$ provide an indirect method of estimating head growth during the intrauterine and neonatal periods and during the first years of life. Head size reflects the growth of the brain and has been associated with body size, brain malformations, or merely be familial factors ${ }^{1}$. Dobbing, in $1974^{2}$, emphasized that brain growth does not occur in a linear and symmetrical fashion but is, instead, characterized by periods of increased cell growth. The human brain experiences two growth spurts. The initial growth spurt occurs from 12 to 18 weeks of gestation and is characterized by neuronal multiplication. The second growth spurt begins at 28 weeks of gestation and extends through birth until the third year of life. This growth is considered the major period of growth of the brain. During these growth spurt phases, the brain is more vulnerable and susceptible to the presence of both internal and external factors that can affect brain and body growth. Davies ${ }^{3}$ argued that $\mathrm{HC}$ is more influenced by genetic factors than by weight and height and that it is less susceptible to maternal factors, such as diabetes, multipara, prior abortions, hypertension, malnutrition, or placental anomalies.

Several studies have investigated HC in newborns and infants and correlated them with maternal, placental, and fetal factors ${ }^{4}$. In fact, previous studies ${ }^{5}$ have reported correlations between $\mathrm{HC}$ and other anthropometric measurements or gestational age (GA). Up until now, few research groups in Brazil have studied HC or its correlation with GA and gender'. Therefore, the aim of this study was to revisit newborn HC 
and to correlate it with GA, gender and the type of delivery so that we could evaluate the data to identify any differences between newborns delivered in public and private maternity hospitals. Moreover, an additional purpose was to build and validate simple graphs and curves that can be used in neonatal clinical practice.

\section{METHODS}

\section{Study design and participants}

This was a prospective neonatal and cross-sectional study that involved examinations performed on singleton live newborns born from 34 to 42 weeks of GA to mothers at public maternity hospitals that assist poor communities, and at two private hospitals that assist communities belonging to the middle and upper social classes. These hospitals serve several cities in the Rio Grande do Norte state, Brazil, and the study included newborns born from 2008 to 2009. The exclusion criteria were the following: infants with malformations of the central nervous system (CNS), chromosomal abnormalities, or congenital infections; mothers with hypertensive disorders of pregnancy, diabetes or gestational diabetes, a history of smoking, or multiple pregnancies; forceps deliveries; undetermined or questionable GA; and mothers who did not agree to participate in the study. Outlier values were defined as measurements that were above or below the mean plus four standard deviations (SD), and were excluded from the study.

\section{Procedures}

To identify significant differences according to GA, we divided the groups according to the health care system used (public and private), gender (male and female), and the type of delivery (vaginal and cesarean). The following socio-demographic variables of the mothers were analyzed: GA, race, education, marital status, family income, number of prenatal visits, and type of delivery (protocol developed by the authors). The mothers were interviewed daily, and the data were analyzed using Microsoft Excel 2007. Head circumference was measured by a pediatric neonatologist (MSTA) and a child neurologist (ANM) within the first 48 hours after birth, while in shared rooms of maternity hospitals, under adequate conditions of light and temperature, in newborns without edema or cephalohematoma. Head circumference was obtained using an inextensible plastic measuring tape that was placed around the external occipital protuberance at the level of the eyebrows and anterior glabella. Measurements were recorded in $\mathrm{cm}$ to two decimal places. The GA was defined as the number of completed weeks from the last menstrual period ${ }^{7}$. This result was compared with the methods described by Capurro et al. ${ }^{8}$ The newborns were selected by a neonatologist when a postnatal clinical examination did not exhibit any alterations. The project was approved by the Research Committee of the Graduate Program in Health Sciences at the Universidade Federal do Rio Grande do Norte. All of the parents or guardians of the newborns who were assessed in the present study signed an informed consent form.

\section{Statistical analysis}

Data analyses were performed using the SPSS 17.0 and R 2.11.1. statistical software programs9. The Student's t test for independent variables was used to identify correlations between mean HC and other factors, including GA, gender, the health system, and the type of delivery. To evaluate the influence of GA, gender, the type of delivery, and the type of health care system on HC, analysis of variance was performed with Tukey's post hoc test. Curves for HC were built for the $10^{\text {th }}, 25^{\text {th }}, 50^{\text {th }}, 75^{\text {th }}, 90^{\text {th }}$, and $95^{\text {th }}$ percentiles of GA and stratified by gender, the health care system, and the type of delivery using the least mean squares (LMS) method ${ }^{10}$. This method assumes that the Box-Cox transformation can be used to convert independent data with positive values into normally-distributed data. The L, M, and S parameters were calculated for each age group and then smoothed using a cubic spline function ${ }^{11}$. The M parameter expressed the median HC for each GA group, the S parameter represented the coefficient of variation for each GA group, and the $\mathrm{L}$ parameter and Box-Cox coefficient were employed to mathematically transform the $\mathrm{HC}$ measurements into normally distributed data for each GA group. The coefficient $\mathrm{L}$ corresponded to a value that minimized the sum of the squared deviations of each variable. Using these three parameters, it was possible to construct curves for any desired percentile with the formula: $\mathrm{C}_{100 a(t)}=\mathrm{M}_{(\mathrm{t})}\left[1+\mathrm{L}_{(\mathrm{t})} \mathrm{S}_{(\mathrm{t})}\right.$ $\left.\mathrm{Z}_{\mathrm{a}}\right]^{1 / \mathrm{L}(\mathrm{t})}$, where $\mathrm{Z}_{\mathrm{a}}$ was the $\mathrm{SD}$ that corresponded to the area "a," $C_{100 a(t)}$ was the percentile that corresponded to $Z_{a}, t$ was the GA, and $\mathrm{L}_{(\mathrm{t})}, \mathrm{M}_{(\mathrm{t})}, \mathrm{S}_{(\mathrm{t})}$, and $\mathrm{C}_{100 \mathrm{a}(\mathrm{t})}$ indicated the corresponding values for each curve at age t. The LMS method was incorporated into the LMS Chart Maker Pro software version $2.3^{12}$. To evaluate the quality of the fit, $\mathrm{Z}$ scores were calculated for each GA using the following formula: $\mathrm{Z}$ score $=\left[(\mathrm{HC} / \mathrm{M}) \cdot \mathrm{L}^{-1}\right] /(\mathrm{LS})$. Because the curves were based on a normal distribution of $\mathrm{Z}$ scores, the mean and SDs were calculated for each GA and were expected to be $0.0 \pm 1.0$. The analysis of the calculated $\mathrm{Z}$ score distributions was used to determine whether the curves adequately fit the data. To validate the curves, the $\mathrm{Z}$ scores, SDs, and confidence intervals (CIs) for each GA were calculated from different samples at random using the LMS parameters obtained for the curves for each GA. Mean and CI values were compared to zero, and the SDs were compared to one (using an alpha of 0.05 for the nine comparisons within each interval). The curves were then evaluated by analyzing the percentage of children who fell within the expected intervals. By definition, approximately $10 \%$ of a population is below the $10^{\text {th }}$ percentile, $80 \%$ is between the $10^{\text {th }}$ and $90^{\text {th }}$ percentiles, 
and $10 \%$ is above the $90^{\text {th }}$ percentile. The curves that were newly-created for $\mathrm{HC}$ were validated using distinct samples for all combined GAs, genders, and types of health care system, and mean and CI values were calculated for each GA.

\section{RESULTS}

The reference population consisted of 4,560 singleton live births. The following groups were excluded from the study: women who did not agree to the study (434/9.51\%); women who underwent a forceps delivery (43/0.94\%); preterm infants in the ICU (180/3.94\%); neonates with CNS malformations (18/0.39\%), congenital anomalies $(22 / 0.48 \%)$, congenital infections $(80 / 1.75 \%)$ or uncertain or undetermined GA (606/13.28\%); newborns born to mothers with hypertensive disorders of pregnancy (200/4.38\%), diabetes or gestational diabetes $(100 / 2.19 \%)$ or multiple pregnancies (30/0.65\%). The study population comprised 2,847 newborns, of whom 1,495 (52.51\%) were male and $1,352(47.49 \%)$ were female. With regard to the health care system used, 697 infants were born in private hospitals, of which 344 (49.35\%) were male and 353 (50.65\%) were female; 555 (79.62\%) were born in the state capital, and 142 (20.38\%) came from other cities; and 686 (99.76\%) were Caucasian and 11 (1.59\%) were Black. In relation to maternal education, 316 (45.33\%) mothers had a high school education, 332 (52.36\%) had a college education, and $49(7.03 \%)$ had only a basic education. With respect to the type of delivery, $626(89.81 \%)$ were cesarean deliveries, and 71 (10.19\%) were vaginal deliveries. Similarly, 2,150 infants were born in public maternity facilities. Of these, $1,151(53.53 \%)$ were male and $999(46.46 \%)$ were female, $1,369(63.67 \%)$ were born in the capital, and $781(36.32 \%)$ came from other cities. With regard to race, 1,973 (91.76\%) were Caucasian and 177 (8.23\%) were Black. With respect to maternal education, 1,273 (59.20\%) had an elementary education, 70 (3.25\%) had a college education, 732 (34.05\%) had a high school education, and 75 (3.48\%) were illiterate. With respect to the type of delivery, 1,311 (60.98\%) were born by cesarean and 839 (39.02\%) were vaginal deliveries.

In the overall analysis, the Student's t tests showed that, according to the type of health care system used, the mean $\mathrm{HC}$ was $34.49 \pm 1.72 \mathrm{~cm}$ for infants born in public maternities and $34.90 \pm 1.34 \mathrm{~cm}$ for infants born in private hospitals and this difference was significant $(\mathrm{p}<0.001)$. With respect to gender, the mean $\mathrm{HC}$ was $34.24 \pm 1.45 \mathrm{~cm}$ in females and $34.91 \pm 1.75 \mathrm{~cm}$ in males, and this difference was significant $(\mathrm{p}<0.001)$. When the mean HC was analyzed according to the type of delivery, it was $34.12 \pm 1.54 \mathrm{~cm}$ and $34.81 \pm 1.65 \mathrm{~cm}$ in children born by vaginal and cesarean delivery, respectively, and this difference was significant $(\mathrm{p}<0.001)$. Another result, that was considered in the comparison between GA and gender, was that no significant differences were observed between the genders in gestational ages from 34-35 weeks.

Table 1 shows comparisons across mean HC according to GA, the type of delivery, gender and the health system. Comparisons were calculated using the Student's t-test. In newborns born at 38 to 41 weeks of pregnancy, the mean $\mathrm{HC}$ was significantly different between those with a cesarean or vaginal birth $(\mathrm{p}<0.001)$. In infants born at 36 to 42 weeks of gestation, the mean $\mathrm{HC}$ was significantly lower in females than in males $(\mathrm{p}<0.001)$. In infants born at 38 to 40 weeks, those born in private maternity hospitals had a significantly larger mean $\mathrm{HC}$ than those born in public maternity hospitals $(\mathrm{p}<0.001)$.

Tables 2-5 show the mean and SD values for these relationships as well as the $10^{\text {th }}$ through $95^{\text {th }}$ percentiles for the $\mathrm{HC}$ curves that were created according to GA for all newborns of both genders, who were born in both healthcare systems (private and public) and who were born by either type of delivery. Table 6 presents the estimates of the LMS values that were calculated according to GA for the general curve and gender.

Table 1. Comparisons of mean head circumference by GA, according health system, gender and type of delivery using the Student's t-test.

\begin{tabular}{|c|c|c|c|c|c|c|c|c|c|c|c|c|c|c|c|c|c|c|c|c|c|}
\hline \multirow{2}{*}{$\begin{array}{l}\text { GA } \\
\text { (weeks) }\end{array}$} & \multicolumn{3}{|c|}{ Cesarean } & \multicolumn{3}{|c|}{ Vaginal } & \multirow{2}{*}{$p$-value } & \multicolumn{3}{|c|}{ Female } & \multicolumn{3}{|c|}{ Male } & \multirow{2}{*}{$p$-value } & \multicolumn{3}{|c|}{ Private } & \multicolumn{3}{|c|}{ Public } & \multirow{2}{*}{$\mathrm{p}$-value } \\
\hline & $n$ & Mean & SD & $n$ & Mean & SD & & $n$ & Mean & SD & $\mathrm{n}$ & Mean & SD & & $n$ & Mean & SD & $\mathrm{n}$ & Mean & SD & \\
\hline 34 & 16 & 31.3 & 1.9 & 19 & 32.0 & 1.3 & 0.159 & 15 & 31.4 & 1.2 & 20 & 31.8 & 1.9 & 0.509 & 4 & 32.0 & 0.8 & 31 & 31.6 & 1.8 & 0.695 \\
\hline 35 & 33 & 32.6 & 1.5 & 35 & 31.9 & 1.6 & 0.074 & 32 & 31.9 & 1.3 & 36 & 32.4 & 1.8 & 0.167 & 12 & 32.9 & 1.4 & 56 & 32.1 & 1.6 & 0.088 \\
\hline 36 & 52 & 32.9 & 1.7 & 50 & 33.0 & 1.5 & 0.858 & 40 & 32.3 & 1.4 & 62 & 33.3 & 1.7 & 0.003 & 27 & 33.7 & 1.7 & 75 & 32.7 & 1.5 & $0.004^{*}$ \\
\hline 37 & 161 & 34.4 & 3.0 & 93 & 33.7 & 1.2 & $0.040 *$ & 111 & 33.5 & 1.3 & 143 & 34.6 & 3.1 & $0.001 *$ & 76 & 34.5 & 1.2 & 178 & 33.9 & 2.9 & 0.145 \\
\hline 38 & 323 & 34.7 & 1.3 & 145 & 33.9 & 1.3 & $0.001 *$ & 221 & 34.0 & 1.3 & 247 & 34.8 & 1.4 & $0.001 *$ & 172 & 34.7 & 1.2 & 296 & 34.3 & 1.4 & $0.001 *$ \\
\hline 39 & 505 & 34.9 & 1.4 & 169 & 34.3 & 1.4 & $0.001 *$ & 329 & 34.4 & 1.3 & 345 & 35.0 & 1.4 & $0.001 *$ & 230 & 35.2 & 1.2 & 444 & 34.5 & 1.4 & $0.001 *$ \\
\hline 40 & 422 & 35.1 & 1.3 & 202 & 34.5 & 1.3 & $0.001 *$ & 310 & 34.5 & 1.2 & 314 & 35.2 & 1.3 & $0.001 *$ & 115 & 35.3 & 1.2 & 509 & 34.8 & 1.4 & $0.001 *$ \\
\hline 41 & 281 & 35.2 & 1.2 & 123 & 34.6 & 1.4 & $0.001^{\star}$ & 194 & 34.6 & 1.2 & 210 & 35.3 & 1.2 & $0.001 *$ & 46 & 35.0 & 1.2 & 358 & 35.0 & 1.3 & 0.943 \\
\hline 42 & 140 & 35.3 & 1.3 & 78 & 35.1 & 1.3 & 0.336 & 100 & 34.8 & 1.3 & 118 & 35.5 & 1.3 & $0.001 *$ & 15.0 & 35.5 & 1.3 & 203 & 35.2 & 1.3 & 0.385 \\
\hline
\end{tabular}


Table 2. Head circumference percentiles by GA of newborns in relation to the general sample and gender.

\begin{tabular}{|c|c|c|c|c|c|c|c|c|c|}
\hline \multirow{2}{*}{$\begin{array}{l}\text { GA } \\
\text { (weeks) }\end{array}$} & \multirow[b]{2}{*}{1} & \multirow{2}{*}{ Mean } & \multirow{2}{*}{ SD } & \multicolumn{6}{|c|}{ Percentiles } \\
\hline & & & & 10th & 25th & 50th & 75th & 90th & 95th \\
\hline \multicolumn{10}{|l|}{ General } \\
\hline 34 & 35 & 1.7 & 1.7 & 29.9 & 30.7 & 31.7 & 32.6 & 33.5 & 34.0 \\
\hline 35 & 68 & 32.2 & 1.6 & 30.7 & 31.5 & 32.5 & 33.4 & 34.3 & 34.8 \\
\hline 36 & 102 & 32.9 & 1.6 & 31.4 & 32.3 & 33.3 & 34.3 & 35.2 & 35.7 \\
\hline 37 & 54 & 34.1 & 2.5 & 32.1 & 33.0 & 34.0 & 35.0 & 35.9 & 36.4 \\
\hline 38 & 468 & 34.5 & 1.4 & 32.5 & 33.4 & 34.5 & 35.5 & 36.4 & 36.9 \\
\hline 39 & 674 & 34.7 & 1.4 & 32.8 & 33.7 & 34.7 & 35.8 & 36.7 & 37.2 \\
\hline 40 & 624 & 34.9 & 1.3 & 32.9 & 33.9 & 34.9 & 35.9 & 36.9 & 37.4 \\
\hline 41 & 404 & 35.0 & 1.3 & 33.1 & 34.0 & 35.0 & 36.1 & 37.0 & 37.6 \\
\hline$\angle$ & 18 & 35.2 & 1.3 & 33.2 & 4.1 & 35.2 & 36.2 & 37.2 & 7.7 \\
\hline \multicolumn{10}{|l|}{ Female } \\
\hline 34 & 15 & 31.4 & 1.2 & 30.1 & 30.8 & 31.6 & 32.4 & 33.2 & 33.6 \\
\hline 35 & 32 & 31.9 & 1.3 & 30.7 & 1.4 & 32.2 & 33.1 & 33.8 & 34.3 \\
\hline 36 & 40 & 32.3 & 1.4 & 31.3 & 32.0 & 32.9 & 33.7 & 34.5 & 34.9 \\
\hline 37 & 111 & 33.5 & 1.3 & 31.8 & 32.6 & 33.5 & 34.3 & 35.1 & 35.5 \\
\hline 38 & 221 & 34.0 & 1.3 & 32.3 & 321 & 34.0 & 34.8 & 35.6 & 36.1 \\
\hline 39 & 329 & 34.4 & 1.3 & 32.7 & 33.5 & 34.3 & 35.2 & 36.0 & 36.5 \\
\hline 4 & 0 & 3 & 1 & 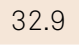 & 33.7 & 6 & 35.5 & 36 & 36.7 \\
\hline 41 & 194 & 34.6 & 1.2 & 33.1 & 33.9 & 34.8 & 35.7 & 36.5 & 36.9 \\
\hline 42 & 100 & 34.8 & 1.3 & 33.2 & 34.0 & 34.9 & 35.8 & 36.6 & 37.1 \\
\hline \multicolumn{10}{|l|}{ Male } \\
\hline 34 & 20 & 31.8 & 1.9 & 30.5 & 31.4 & 32.4 & 33.4 & 34.3 & 34.9 \\
\hline 5 & 36 & 32.4 & 1.8 & 31.1 & 32.0 & 33.1 & 34.1 & 35.0 & 35.6 \\
\hline 6 & 62 & 3 & 1 & 31.7 & 32.7 & 33.7 & 34.8 & 35 & 36.3 \\
\hline 7 & 143 & 34.6 & 3.1 & 32.2 & 33.2 & 34.3 & 5.4 & 36.3 & 6.9 \\
\hline 38 & 247 & 34.8 & 1.4 & 32.6 & 33.6 & 34.7 & 35.8 & 36.8 & 31.4 \\
\hline 39 & 345 & 35.0 & 1.4 & 32.9 & 33.9 & 35.0 & 36.1 & 37.1 & 3.7 \\
\hline 40 & 314 & 35.2 & 1.3 & 33.1 & 34.1 & 35.2 & 36.3 & 37.3 & 37.9 \\
\hline 41 & 210 & 35.3 & 1.2 & 33.3 & 34.3 & 35.4 & 36.5 & 37.5 & 38.1 \\
\hline 42 & 118 & 35.5 & 1.3 & 33.4 & 34.4 & 35.6 & 36.7 & 37.7 & 38.3 \\
\hline
\end{tabular}

GA: gestational age.

\section{DISCUSSION}

This analysis of neonatal HC enabled us to create a set of curves of fetal intrauterine growth that are based solely on HC as a function of GA, considering that $\mathrm{HC}$ is essential during routine examination of newborns, and reflects fetal and postnatal brain growth. Anthropometry undoubtedly remains a simple, universal, noninvasive, and inexpensive method to assess brain growth. Measuring $\mathrm{HC}$ during the neonatal period is the most sensitive method available to assess brain growth from birth, especially in the first year of life, because it reflects, to some extent, intrauterine CNS development. This makes it the most important parameter to monitor neurodevelopment after birth $^{13,14}$. We performed a prospective neonatal cross-sectional
Table 3. Head circumference percentiles by the GA of Brazilian newborns in relation to the general sample of the private health system and gender.

\begin{tabular}{|c|c|c|c|c|c|c|c|c|c|}
\hline \multirow{2}{*}{$\begin{array}{l}\text { GA } \\
\text { (weeks) }\end{array}$} & \multirow{2}{*}{$\mathrm{n}$} & \multirow{2}{*}{ Mean } & \multirow{2}{*}{ SD } & \multicolumn{6}{|c|}{ Percentiles } \\
\hline & & & & 10th & 25th & 50 th & 75th & 90th & 95th \\
\hline \multicolumn{10}{|l|}{ General } \\
\hline 34 & 4 & 32.0 & 0.8 & 30.8 & 31.5 & 32.3 & 33.1 & 33.8 & 34.2 \\
\hline 35 & 12 & 32.9 & 1.4 & 31.5 & 32.3 & 33.1 & 33.9 & 34.6 & 35.0 \\
\hline 36 & 27 & 33.7 & 1.7 & 32.2 & 33.0 & 33.8 & 34.6 & 35.3 & 35.8 \\
\hline 37 & 76 & 34.5 & 1.2 & 32.8 & 33.5 & 34.4 & 35.2 & 35.9 & 36.4 \\
\hline 38 & 172 & 34.7 & 1.2 & 33.2 & 34.0 & 34.8 & 35.6 & 36.4 & 36.9 \\
\hline 39 & 230 & 35.2 & 1.2 & 33.5 & 34.3 & 35.1 & 36.0 & 36.7 & 37.2 \\
\hline 40 & 115 & 35.3 & 1.2 & 33.7 & 34.4 & 35.3 & 36.1 & 36.9 & 37.4 \\
\hline 41 & 46 & 35.0 & 1.2 & 33.7 & 34.4 & 35.3 & 36.2 & 36.9 & 37.4 \\
\hline 42 & 15 & 35.5 & 1.3 & 33.7 & 34.5 & 35.3 & 36.2 & 37.0 & 37.4 \\
\hline \multicolumn{10}{|l|}{ Female } \\
\hline 34 & 2 & 32.0 & 1.4 & 31.0 & 31.7 & 32.4 & 33.2 & 33.8 & 34.2 \\
\hline 35 & 6 & 33.5 & 0.6 & 31.5 & 32.2 & 32.9 & 33.6 & 34.3 & 34.7 \\
\hline 36 & 14 & 33.0 & 1.3 & 31.9 & 32.6 & 33.3 & 34.1 & 34.8 & 35.2 \\
\hline 37 & 31 & 33.9 & 1.0 & 32.4 & 33.1 & 33.8 & 34.6 & 35.3 & 35.7 \\
\hline 38 & 81 & 34.3 & 1.2 & 32.9 & 33.6 & 34.3 & 35.1 & 35.8 & 36.2 \\
\hline 39 & 119 & 34.8 & 1.2 & 33.3 & 34.0 & 34.8 & 35.5 & 36.2 & 36.7 \\
\hline 40 & 67 & 35.1 & 1.2 & 33.5 & 34.2 & 35.0 & 35.8 & 36.5 & 36.9 \\
\hline 41 & 25 & 34.8 & 1.1 & 33.5 & 34.2 & 35.0 & 35.8 & 36.5 & 36.9 \\
\hline 42 & 8 & 34.9 & 1.1 & 33.4 & 34.2 & 35.0 & 35.7 & 36.5 & 36.9 \\
\hline \multicolumn{10}{|l|}{ Male } \\
\hline 34 & 2 & 32.0 & 0.0 & 31.3 & 32.0 & 32.8 & 33.5 & 34.2 & 34.6 \\
\hline 35 & 6 & 32.3 & 1.8 & 32.0 & 32.7 & 33.5 & 34.3 & 35.0 & 35.4 \\
\hline 36 & 13 & 34.5 & 1.9 & 32.7 & 33.4 & 34.2 & 35.0 & 35.7 & 36.1 \\
\hline 37 & 45 & 34.9 & 1.2 & 33.2 & 33.9 & 34.7 & 35.6 & 36.3 & 36.7 \\
\hline 38 & 91 & 35.1 & 1.2 & 33.6 & 34.4 & 35.2 & 36.0 & 36.7 & 37.2 \\
\hline 39 & 111 & 35.6 & 1.2 & 33.9 & 34.7 & 35.5 & 36.3 & 37.1 & 37.5 \\
\hline 40 & 48 & 35.7 & 1.1 & 34.1 & 34.9 & 35.7 & 36.5 & 37.3 & 37.7 \\
\hline 41 & 21 & 35.4 & 1.3 & 34.2 & 35.0 & 35.8 & 36.7 & 37.4 & 37.9 \\
\hline 42 & 7 & 36.2 & 1.2 & 34.4 & 35.1 & 35.9 & 36.8 & 37.5 & 38.0 \\
\hline
\end{tabular}

study that allowed us to obtain an accurate assessment of GA and HC. Despite its limitations, this is one of the most widelyaccepted methods used to create growth curves that are aimed at determining $\mathrm{HC}$ at birth and post-birth ${ }^{15}$. We studied the following two distinct population groups: families of lower socioeconomic status who were assisted by the public health care system in the Maternity Hospital of the Universidade Federal do Rio Grande do Norte, which is a reference hospital in Natal, Brazil, and families of higher socioeconomic status who were served by the private health care system. It was, therefore, possible to determine differences in $\mathrm{HC}$ at birth that were based on the distinct social class into which the infant was born. The exclusion criteria allowed us to obtain a sample of singleton, healthy newborns and to create standard growth curves that 
Table 4. Head circumference percentiles of newborns in relation to the general sample of the public health system and gender.

\begin{tabular}{|c|c|c|c|c|c|c|c|c|c|}
\hline \multirow{2}{*}{$\begin{array}{l}\text { GA } \\
\text { (weeks) }\end{array}$} & \multirow{2}{*}{$\mathrm{n}$} & \multirow{2}{*}{ Mean } & \multirow{2}{*}{ SD } & \multicolumn{6}{|c|}{ Percentiles } \\
\hline & & & & 10th & 25th & 50th & 75th & 90th & 95th \\
\hline \multicolumn{10}{|l|}{ General } \\
\hline 34 & 31 & 31.6 & 1.8 & 30.0 & 30.9 & 31.9 & 32.9 & 33.8 & 34.3 \\
\hline 35 & 56 & 32.1 & 1.6 & 30.6 & 31.5 & 32.5 & 33.5 & 34.4 & 35.0 \\
\hline 36 & 75 & 32.7 & 1.5 & 31.2 & 32.1 & 33.2 & 34.2 & 35.1 & 35.7 \\
\hline 37 & 178 & 33.9 & 2.9 & 31.7 & 32.7 & 33.7 & 34.8 & 35.7 & 36.3 \\
\hline 38 & 296 & 34.3 & 1.4 & 32.2 & 33.1 & 34.2 & 35.2 & 36.2 & 36.8 \\
\hline 39 & 444 & 34.5 & 1.4 & 32.5 & 33.5 & 34.5 & 35.6 & 36.6 & 37.1 \\
\hline 40 & 509 & 34.8 & 1.4 & 32.8 & 33.7 & 34.8 & 35.9 & 36.8 & 37.4 \\
\hline 41 & 358 & 35.0 & 1.3 & 33.0 & 33.9 & 35.0 & 36.1 & 37.1 & 37.7 \\
\hline 42 & 203 & 35.2 & 1.3 & 33.2 & 34.2 & 35.2 & 36.3 & 37.3 & 37.9 \\
\hline \multicolumn{10}{|l|}{ Female } \\
\hline 34 & 13 & 31.4 & 1.3 & 29.8 & 30.5 & 31.4 & 32.2 & 32.9 & 33.3 \\
\hline 35 & 26 & 31.6 & 1.2 & 30.4 & 31.2 & 32.0 & 32.8 & 33.6 & 34.0 \\
\hline 36 & 26 & 32.0 & 1.4 & 31.0 & 31.8 & 32.6 & 33.5 & 34.3 & 34.7 \\
\hline 37 & 80 & 33.4 & 1.4 & 31.6 & 32.4 & 33.3 & 34.1 & 34.9 & 35.4 \\
\hline 38 & 140 & 34.0 & 1.3 & 32.1 & 32.9 & 33.8 & 34.7 & 35.4 & 35.9 \\
\hline 39 & 210 & 34.3 & 1.4 & 32.5 & 33.3 & 34.2 & 35.1 & 35.9 & 36.3 \\
\hline 40 & 243 & 34.4 & 1.2 & 32.8 & 33.6 & 34.5 & 35.4 & 36.2 & 36.6 \\
\hline 41 & 169 & 346 & 1.3 & 33.0 & 33.8 & 34.7 & 35.6 & 36.4 & 36.9 \\
\hline 42 & 92 & 34.8 & 1.26 & 33.2 & 34.0 & 34.9 & 35.8 & 36.6 & 37.1 \\
\hline \multicolumn{10}{|l|}{ Male } \\
\hline 34 & 18 & 31.8 & 2.0 & 30.2 & 31.2 & 32.3 & 33.3 & 34.3 & 34.9 \\
\hline 35 & 30 & 32.5 & 1.8 & 30.8 & 31.8 & 32.9 & 34.0 & 35.0 & 35.6 \\
\hline 36 & 49 & 33.0 & 1.5 & 31.4 & 32.4 & 33.5 & 34.6 & 35.7 & 36.2 \\
\hline 37 & 98 & 34.5 & 3.6 & 31.9 & 33.0 & 34.1 & 35.2 & 36.2 & 36.9 \\
\hline 38 & 156 & 34.6 & 1.4 & 32.3 & 33.4 & 34.5 & 35.7 & 36.7 & 37.3 \\
\hline 39 & 234 & 34.8 & 1.4 & 32.6 & 33.7 & 34.8 & 36.0 & 37.0 & 37.7 \\
\hline 40 & 266 & 35.2 & 1.4 & 32.9 & 33.9 & 35.1 & 36.3 & 37.3 & 38.0 \\
\hline 41 & 189 & 35.4 & 1.2 & 33.1 & 34.2 & 35.3 & 36.5 & 37.6 & 38.2 \\
\hline 42 & 111 & 35.5 & 1.3 & 33.3 & 34.4 & 35.5 & 36.7 & 37.8 & 38.4 \\
\hline
\end{tabular}

represented an estimate of optimal intrauterine growth. There is no doubt that constructing intrauterine growth curves for a particular population can reveal proper profiles and that this method can allow us to avoid potential errors that arise from classifying newborns based on curves that are not appropriate for evaluating a particular population group ${ }^{16}$.

Revisiting the $\mathrm{HC}$ of newborns, our results corroborate previous findings regarding mean $\mathrm{HC}^{15,17,18,19,20}$. By analyzing the two sample groups in this study, we observed that the

Table 5. Head circumference percentiles by gestational age of newborns in relation to the general sample according to type of delivery.

\begin{tabular}{|cccccccccccc|}
\hline \multirow{2}{*}{$\begin{array}{l}\text { GA } \\
\text { (weeks) }\end{array}$} & $n$ & Mean & SD & \multicolumn{6}{c|}{ Percentiles } \\
\cline { 6 - 12 } & & & & 10th & 25th & 50th & 75th & 90th & 95 th \\
\hline Cesarean & & & & & & & & \\
\hline 34 & 16 & 31.3 & 1.9 & 30.4 & 31.3 & 32.3 & 33.2 & 34.1 & 34.6 \\
\hline 35 & 33 & 32.6 & 1.5 & 31.0 & 31.9 & 32.9 & 33.9 & 34.8 & 35.4 \\
\hline 36 & 52 & 32.9 & 1.7 & 31.7 & 32.6 & 33.6 & 34.6 & 35.5 & 36.1 \\
\hline 37 & 161 & 34.4 & 3.0 & 32.2 & 33.1 & 34.2 & 35.2 & 36.1 & 36.7 \\
\hline 38 & 323 & 34.7 & 1.3 & 32.6 & 33.6 & 34.6 & 35.6 & 36.6 & 37.1 \\
\hline 39 & 505 & 34.9 & 1.4 & 32.9 & 33.8 & 34.9 & 35.9 & 36.9 & 37.5 \\
\hline 40 & 422 & 35.1 & 1.3 & 33.1 & 34.0 & 35.1 & 36.2 & 37.1 & 37.7 \\
\hline 41 & 281 & 35.2 & 1.2 & 33.2 & 34.2 & 35.2 & 36.3 & 37.3 & 37.8 \\
\hline 42 & 140 & 35.3 & 1.3 & 33.3 & 34.3 & 35.4 & 36.4 & 37.4 & 38.0 \\
\hline
\end{tabular}
Vaginal

\begin{tabular}{llllllllll}
34 & 19 & 32.0 & 1.3 & 30.3 & 31.1 & 31.9 & 32.8 & 33.6 & 34.1 \\
35 & 35 & 31.9 & 1.6 & 30.8 & 31.6 & 32.5 & 33.4 & 34.1 & 34.6 \\
36 & 50 & 33.0 & 1.5 & 31.3 & 32.1 & 33.0 & 33.9 & 34.7 & 35.2 \\
37 & 93 & 33.7 & 1.2 & 31.8 & 32.6 & 33.5 & 34.4 & 35.2 & 35.7 \\
38 & 145 & 33.9 & 1.3 & 32.1 & 33.0 & 33.9 & 34.8 & 35.6 & 36.1 \\
39 & 169 & 34.3 & 1.4 & 32.5 & 33.3 & 34.2 & 35.2 & 36.0 & 36.5 \\
40 & 202 & 34.5 & 1.3 & 32.7 & 33.6 & 34.5 & 35.4 & 36.3 & 36.8 \\
41 & 123 & 34.6 & 1.4 & 33.0 & 33.8 & 34.8 & 35.7 & 36.6 & 37.1 \\
42 & 78 & 35.1 & 1.3 & 33.2 & 34.1 & 35.0 & 36.0 & 36.8 & 37.4 \\
\hline
\end{tabular}

Table 6. Estimates of LMS values by GA for the general curve and gender.

\begin{tabular}{|c|c|c|c|c|c|c|c|c|c|c|c|c|}
\hline \multirow{2}{*}{$\begin{array}{l}\text { GA } \\
\text { (weeks) }\end{array}$} & \multicolumn{4}{|c|}{ General } & \multicolumn{4}{|c|}{ Male } & \multicolumn{4}{|c|}{ Female } \\
\hline & $n$ & $L$ & $M$ & $S$ & $\mathrm{n}$ & $\mathrm{L}$ & $M$ & $S$ & $\mathrm{n}$ & L & $M$ & $S$ \\
\hline 34 & 35 & 1 & 31.728 & 0.062 & 20 & 1 & 32.396 & 0.467 & 15 & 1 & 31.615 & 0.0379 \\
\hline 35 & 68 & 1 & 32.513 & 0.058 & 36 & 1 & 33.067 & 0.467 & 32 & 1 & 32.247 & 0.0379 \\
\hline 36 & 102 & 1 & 33.281 & 0.055 & 62 & 1 & 33.716 & 0.467 & 40 & 1 & 32.872 & 0.0379 \\
\hline 37 & 254 & 1 & 33.960 & 0.051 & 143 & 1 & 34.289 & 0.467 & 111 & 1 & 33.461 & 0.0379 \\
\hline 38 & 468 & 1 & 34.436 & 0.047 & 247 & 1 & 34.722 & 0.467 & 221 & 1 & 33.962 & 0.0379 \\
\hline 39 & 674 & 1 & 34.730 & 0.044 & 345 & 1 & 35.024 & 0.467 & 329 & 1 & 34.335 & 0.0379 \\
\hline 40 & 624 & 1 & 34.913 & 0.040 & 314 & 1 & 35.239 & 0.467 & 310 & 1 & 34.586 & 0.0379 \\
\hline 41 & 404 & 1 & 35.061 & 0.036 & 210 & 1 & 35.408 & 0.467 & 194 & 1 & 34.768 & 0.0379 \\
\hline 42 & 218 & 1 & 35.216 & 0.033 & 118 & 1 & 35.562 & 0.467 & 100 & 1 & 34.931 & 0.0379 \\
\hline
\end{tabular}

LMS: least mean squares; GA: gestational age. 


\section{A}
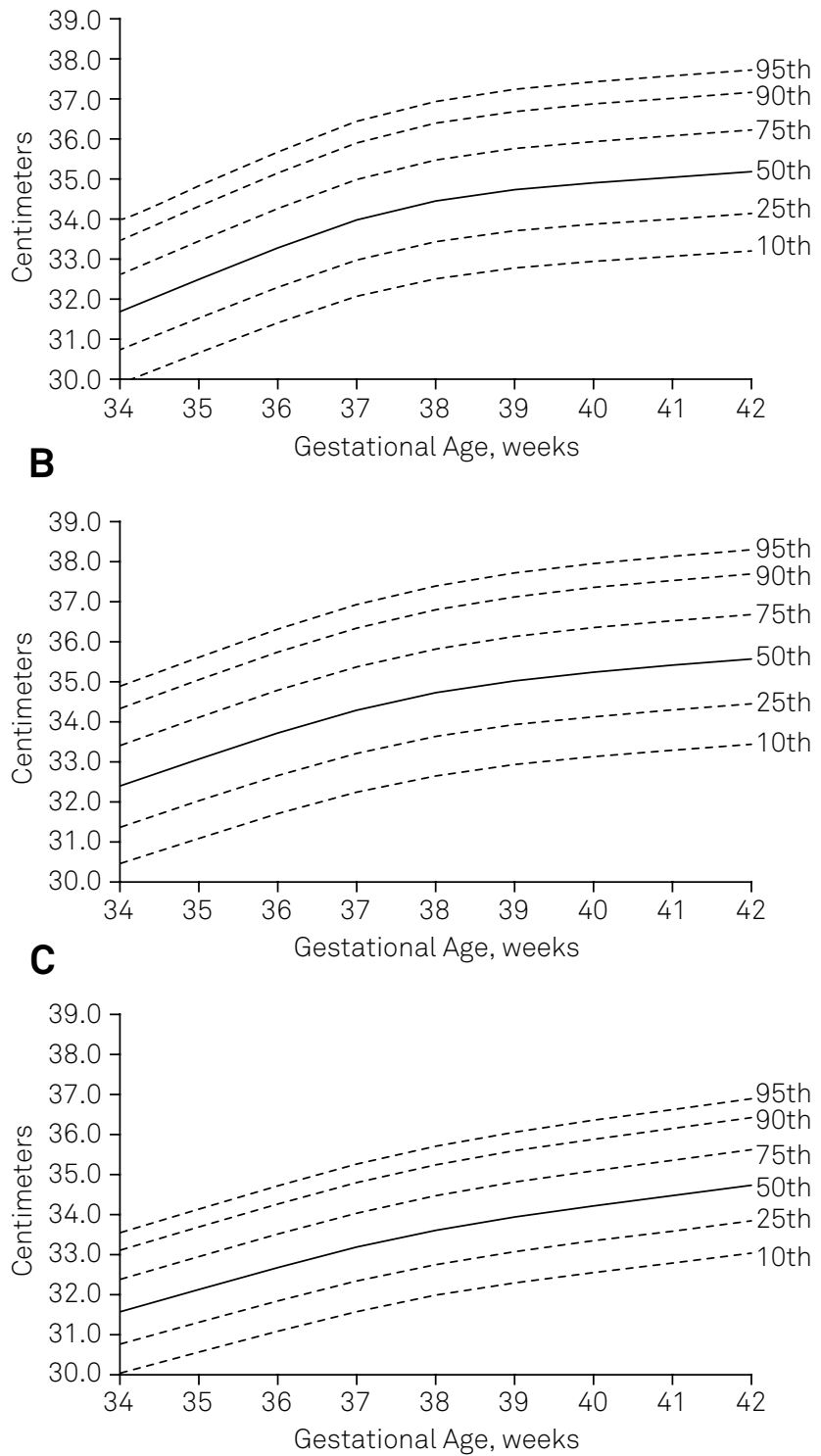

Figure 1. Intrauterine growth curves of head circumference by gestational age, in relation to the general sample (A), males (B) and females (C).

mean $\mathrm{HC}$ of children born in private maternity hospitals was higher across all of the parameters studied in relation to those born in public maternity hospitals. These data are consistent with a study by Hackman et al. ${ }^{21}$, in which socioeconomic status determined not only the social class and strongly influenced the experiences of pregnant women, but which may have affected the future of their newborns through adulthood. These authors argue that lower socioeconomic status during the prenatal period is correlated with premature births and a compromised mental state and academic performance in the future. The lower socioeconomic conditions and lower level of education of the pregnant women who were assisted at the public maternity hospitals meant that they had reduced access to information. Both of these factors could mean that the mother
A
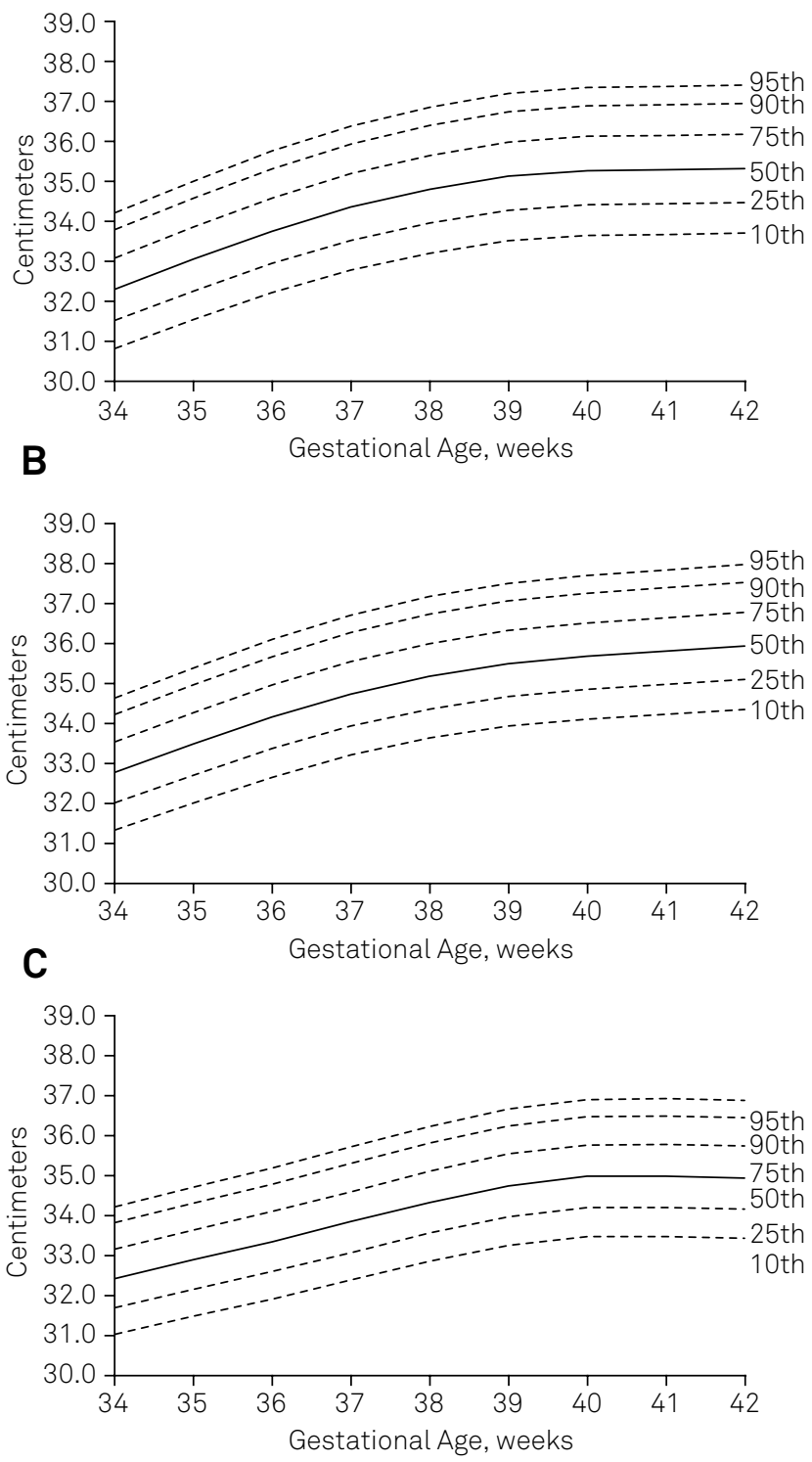

Figure 2. Intrauterine growth curves of head circumference by gestational age according to the private health system: general (A), males (B), and females (C).

was not aware of the importance of prenatal care or of factors that could impair intrauterine brain growth, and this lack of knowledge could result in a reduction in $\mathrm{HC}$ at birth. The present study corroborated the observation that mothers who were assisted in the public health care system were more likely to have inadequate nutrition and to live in stressful environments. These factors may explain, to some extent, the larger HC observed in infants born to mothers with higher socioeconomic status. The HCs of males were observed to be larger than those of females in both preterm and term infants, and these results in male newborns were similar to the results reported in previous studies ${ }^{10,11,12,13,14,15,16,17,18,19,20,21,22,23,24}$. Whitehouse et al. ${ }^{25}$ measured free testosterone levels in the umbilical cord blood and demonstrated that these levels were inversely 
A
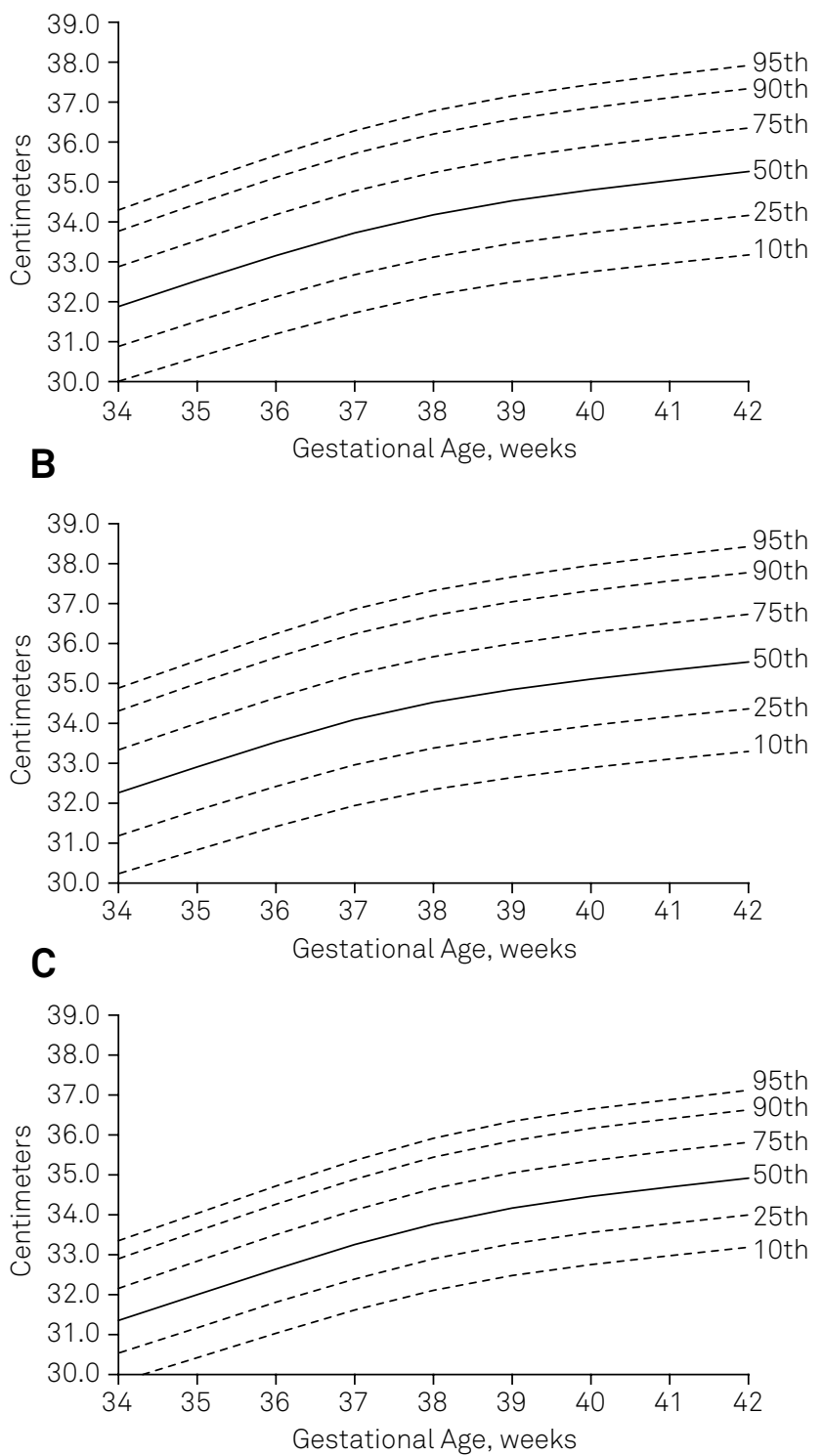

Figure 3. Intrauterine growth curves of head circumference by gestational age according to the public health system: general (A), males (B), and females (C).

correlated with $\mathrm{HC}$ growth in female infants during brain growth in utero and with brain development during infancy. Gur et al. ${ }^{26}$ argued that increased intracranial volume is associated with a proportional increase in gray and white matter in male infants, whereas increased white matter is observed at a lower rate in females. Lombardo et al. ${ }^{27}$ concluded that fetal testosterone levels could influence specific brain regions that later developed into sexually dimorphic gray matter. In addition, the mean HCs observed in this study in males and females in the $10^{\text {th }}, 25^{\text {th }}, 50^{\text {th }}, 75^{\text {th }}$, and $90^{\text {th }}$ percentiles in infants born at 34 to 41 weeks of gestation were similar to the values obtained by Olsen et al. ${ }^{15}$.

We observed that $\mathrm{HC}$ was larger in infants born via cesarean deliveries that were performed in public and private hospitals at 38 to 41 weeks of gestation. To the best of our knowledge, this difference has not been previously reported in the literature. One explanation is that HC may temporarily be reduced during vaginal deliveries for anatomical reasons such as the passage of the newborn through the birth canal or because of fetal presentation This observation partly explains the fact that women prefer this type of delivery because it is less painful.

Cesarean deliveries have increased in Natal, Brazil in parallel with improved socioeconomic conditions and increased education among pregnant women. This higher demand for cesareans is likely based on the belief that the quality of obstetric care is strongly associated with the technology that is used to perform cesarean deliveries. The rate is higher than would be expected for the level of risk, but it is consistent with worldwide trends ${ }^{28}$.

The sample of preterm births in this study was small because of the selection criteria, which required preterm infants to have no clinical or neurological complications. However, it was possible to perform a statistical analysis and construct percentile curves similar to those described in a study by Fenton ${ }^{29}$. A comparison performed using a visual analysis of the curves for $\mathrm{HC}$ in preterm infants revealed that between the ages of 34-36 weeks gestation, $\mathrm{HC}$ is slightly higher in males. These curves are similar to those described by Fenton et al. ${ }^{29}$ and in the study performed by the INTERGROWTH- $21^{\text {st }}$ Project $^{20}$. However, in our study, we observed no significant differences between genders in preterm infants born between 34-35 weeks of age. The knowledge of these data contributes to the analysis of HC in clinical practice of preterm infants. A larger sample size would more accurately reveal the true significance of our observations. These data have not previously been reported, and we have clinically verified these data and corroborated them using statistical analyses. Ulrich ${ }^{30}$ reported that the association between $\mathrm{HC}$ and gender begins during the $30^{\text {th }}$ week of gestation and that this can partially be explained as an effect of steroid hormones on brain structures in male fetuses. However, the author of that study did not specify whether the reported correlation was significant. In addition, in a systematic review by Fenton and $\mathrm{Kim}^{29}$ that included a meta-analysis and growth charts for development in preterm infants, the authors did not discuss these differences.

As shown in Figure 2, comparisons between percentile curves that were obtained using the LMS method have, in general, provided close approximations of the percentiles that are expected in a normal distribution. These results indicate that these curves are well adjusted to the experimental data and that they can, therefore, be used to adjustment of population data.

Finally, the limitations of this study include its crosssectional study method, as pointed out at the beginning of the discussion, and the restriction of our sample population to preterm infants. We emphasize, however, that these 


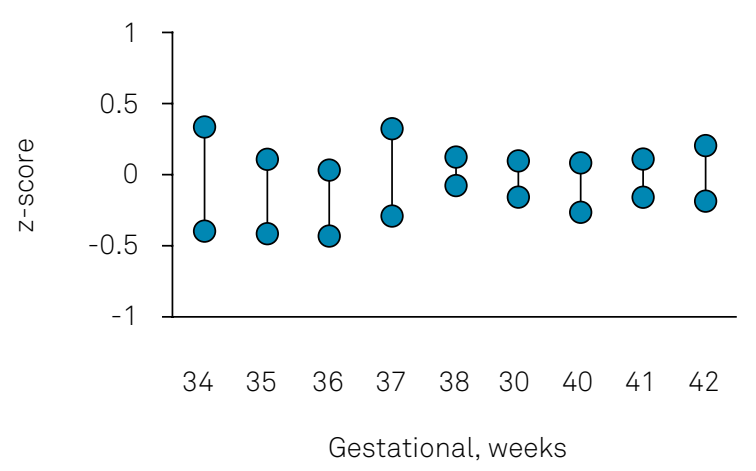

A1 - Confidence intervals at 99,45\% for the average z-score (using $\alpha$ adjusted to 0.0056 and 9 comparisons) by gestational age of head circumference to validate the new curves for all newborns ( $\mathrm{N}=2847)$.

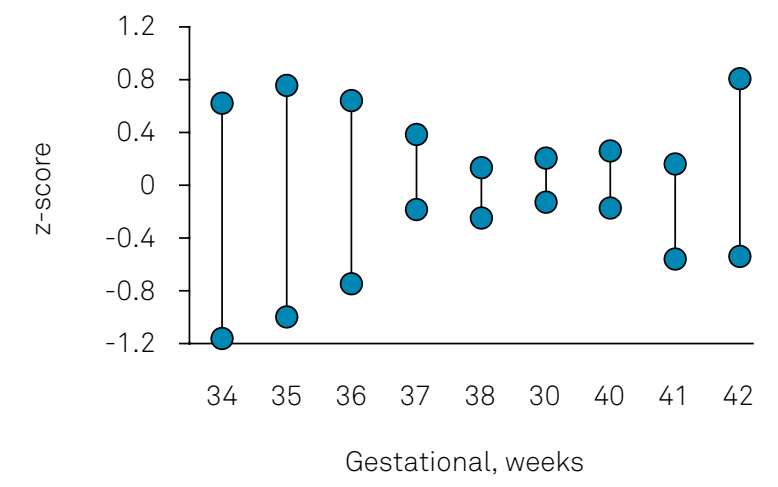

B1 - Confidence intervals at $99.45 \%$ for the average $z$-score for gestational age to validate the new curves for the private health care system.

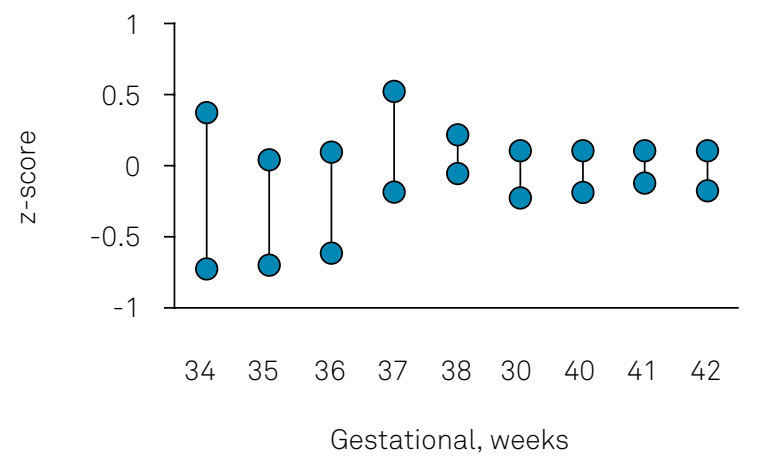

C1 - Confidence intervals at $99.45 \%$ for the average $z$-score for gestational age to validate the new curves for the public health care system.

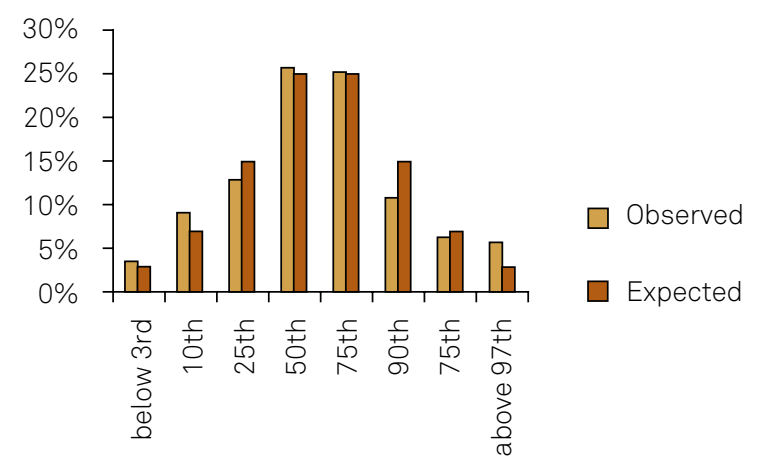

A2 - Comparison of the observed and expected percentiles for the validation of the new curves for all newborns.

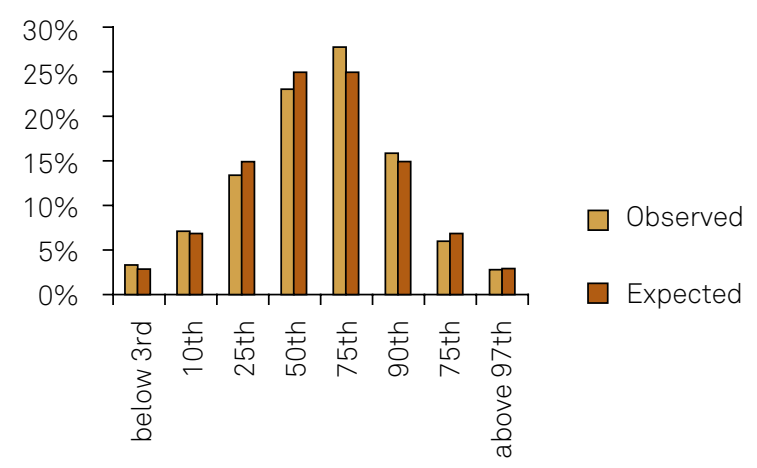

B2 - Comparison of the expected and observed percentiles for the validation of the new curves for the private health care system.

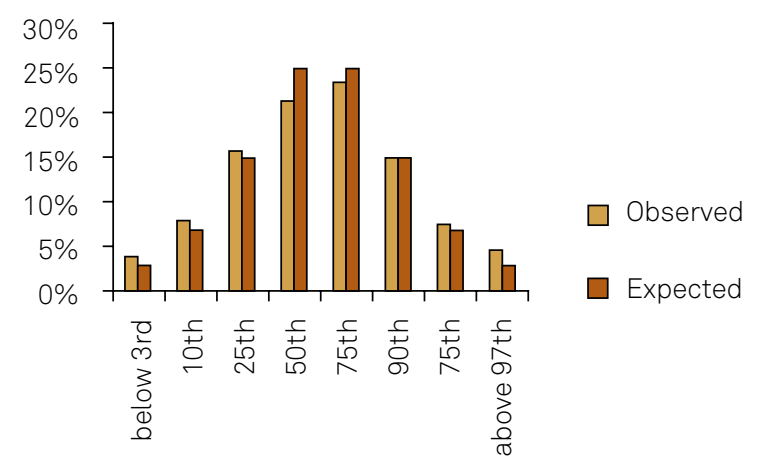

C2 - Comparison of the expected and observed percentiles for the validation of the new curves for the public health care system.

Figure 4. Differentiation of the revalidation curves for all newborns according to gestational age and percentiles in males and females and type of deliveries (method least mean squares:LMS).

limitations do not discredit the current findings because we were able to create curves and graphs that were then validated in statistical analyses.

Revisiting newborn $\mathrm{HC}$, we observed two findings for which there were no references in the literature: a) there was no significant difference between males and females in the gestational ages of 34-35 weeks and b) HC was significantly different between newborns born via cesarean delivery when compared with vaginal delivery. These findings raise new questions and should be used as a reference for other studies. An important consequence of the present study is that our analyses allowed us to generate curves and statistically-validated graphs that can be used in neonatal clinical practice. 
1. García-Alix A, Sáenz-de Pipaón M, Martínez M, Salas-Hernández S, Quero J. [Ability of neonatal head circumference to predict long-term neurodevelopmental outcome]. Rev Neurol. 2004;39(6):548-54. Spanish.

2. Dobbing J. The later growth of the brain and its vulnerability. Pediatrics. 1974;53(1):2-6.

3. Davies DP. Size at birth and growth in the first year of life of babies who are overweight and underweight at birth. Proc Nutr Soc. 1980,39(1):25-33. https://doi.org/10.1079/PNS19800005

4. Lunde A, Melve KK, Gjessing HK, Skjaerven R, Irgens LM. Genetic and Genetic and environmental influences on birth weight, birth length, head circumference, and gestational age by use of population-based parent-offspring data. Am J Epidemiol. 2007:165 (7):734-41. https://doi.org/10.1093/aje/kwk107

5. Lubchenco LO, Hansman C, Boyd E. Intrauterine growth in length and head circumference as estimated from live births at gestational ages from 26 to 42 weeks. Pediatrics. 1966;37(3):403-8.

6. Oliveira HA, Paixão AC, Paixão MO, Barros VCF. [Anthropometric cranial measurements of normal newborn in Sergipe - Northeast of Brazil]. Arq Neuropsiquiatr. 2007;65(3B):896-9. Portuguese. https://doi.org/10.1590/S0004-282X2007000500034

7. Engle WA. Age terminology during the perinatal period. Pediatrics. 2004;114(5):1362-4. https://doi.org/10.1542/peds.2004-1915

8. Capurro H, Konichezky S, Fonseca D, Caldeyro-Barcia R. A simplified method for diagnosis of gestational age in the newborn infant.J Pediatr.1978;93(1):120-2. https://doi.org/10.1016/S0022-3476(78)80621-0

9. Development Core Team. R: a language and environment for statistical computing .R Foundation for Statistical Computing; [cited 2012 Oct 8) Available from: https://www.r-project.org/

10. Cole TJ, Green PJ. Smoothing reference centile curves: the LMS method and penalized likelihood. Stat Med. 1992;11(10):1305-19. https://doi.org/10.1002/sim.4780111005

11. Cole TJ, Freeman JV, Preece MA. British 1990 growth reference centiles for weight, height, body mass index, and head circumference fitted by maximum penalized likelihood. Stat Med. 1998;17(4):407-29. https://doi.org/10.1002/(SICI)10970258(19980228)17:4<407::AID-SIM742>3.0.C0;2-L

12. Pan H, Cole TJ. LMS chart maker: a program to construct growth references using the LMS method. London: Medical Research Council; 2006.

13. Macchiaverni LML, Barros AAF. Perímetro craniano: por que medir sempre. Medicina (Ribeirão Preto). 1998;31(4):595-609. http://dx.doi.org/10.11606/issn.2176-7262.v31i4p595-609

14. Gale CR, O'Callaghan FJ, Godfrey KM, Law CM, Martyn CN. Critical periods of brain growth and cognitive function in children. Brain. 2004;127(2):321-9. https://doi.org/10.1093/brain/awh034

15. Olsen IE, Groveman SA, Lawson ML, Clark RH, Zemel BS. New intrauterine growth curves based on United States data. Pediatrics. 2010;125(2):214-24. https://doi.org/10.1542/peds.2009-0913

16. Fok TF, So HK, Wong E, Ng PC, Chang A, Lau J et al. Updated gestational age specific birth weight, crown-heel length, and head circumference of Chinese newborns. Arch Dis Child Fetal Neonatal Ed. 2003;88(3):229-36. https://doi.org/10.1136/fn.88.3.F229
17. Margotto PR. [Intrauterine growth curves: study of 4413 single live births of normal pregnancies]. J Pediatr (Rio J). 1995;71 (1):11-21. Portuguese. https://doi.org/10.2223/JPED.696

18. Mota M, Melo A, Burak C, Daltro C, Rodrigues B, Lucena R. Anthropometric cranial measures of normal newborn. Arq Neuropsiquiatr. 2004;62(3A):626-9. https://doi.org/10.1590/S0004-282X2004000400011

19. Yudkin PL, Aboualfa M, Eyre JA, Redman CW, Wilkinson AR. New birthweight and head circumference centiles for gestational ages 24 to 42 weeks. Early Hum Dev. 1987;15(1):45-52. https://doi.org/10.1016/0378-3782(87)90099-5

20. Villar J, Cheikh Imail L, Victora CG, Ohuma EO, Bertino E, Altman DG et. al. International standards for newborn weight, length, and head circumference by gestational age and sex: the Newborn Cross-Sectional Study of the INTERGROWTH-21st Project. Lancet. 2014;384(9946):857-68. https://doi.org/10.1016/S0140-6736(14)60932-6

21. Hackman DA, Farah MJ, Meaney MJ. Socioeconomic status and the brain: mechanistic insights from human and animal research. Nat Rev Neurosci. 2010;11(9):651-9. https://doi.org/10.1038/nrn2897

22. Britton JR, Britton HL, Jennet R, Gaines J, Daily WJ. Weight, length, head, and chest circumference at birth in Phoenix, Arizona.J Reprod Med. 1993;38(3):215-22.

23. Kierans WJ, Kendall P, Foster LT, Liston RM, Tuk T. New birth body length and head circumference charts for the British Columbia population. BCMJ. 2007;49(2):72-7.

24. Sivan Y, Merlob P, Reisner SH. Head measurements in newborn infants. J Craniofac Genet Dev Biol. 1984;4(4):259-63.

25. Whitehouse AJO, Maybery MT, Hart R, Sloboda DM, Stanley FJ, Newnham JP, et al. Free testosterone levels in umbilical-cord blood predict infant head circumference in females. Dev Med Child Neurol. 2010;52(3):e73-7. https://doi.org/10.1111/j.1469-8749.2009.03546.x

26. Gur RC, Turetsky BI, Matsui M, Yan M, Bilker W, Hughett P et al. Sex differences in brain gray and white matter in healthy young adults: correlations with cognitive performance. J Neurosci. 1999;19(10):4065-72.

27. Lombardo MV, Ashwin E, Auyeung B, Chakrabarti B, Taylor K, Hackett G, et al. Fetal testosterone Influences sexually dimorphic gray matter in the human brain. J Neurosci 2012;32(2):674-80. https://doi.org/10.1523/JNEUROSCI.4389-11.2012

28. Mandarino NR, Chein MB, Monteiro Júnior F, Brito LM, Lamy ZC, Nina VJ et al. [Aspects related to choice of type of delivery: a comparative study of two maternity hospitals in São Luís, State of Maranhão, Brazil]. Cad Saúde Pública. 2009;25(7):1587-96. Portuguese. https://doi.org/10.1590/S0102-311X2009000700017

29. Fenton TR, Kim H. A systematic review and meta-analysis to revise the Fenton growth chart for preterm infants. BMC Pediatrics. 2013;13(1):59. https://doi.org/10.1186/1471-2431-13-59

30. Ulrich M. Fetal growth patterns in a population of Danish newborn infants. Acta Paediatr Scand Suppl. 1982;292:1-45. 